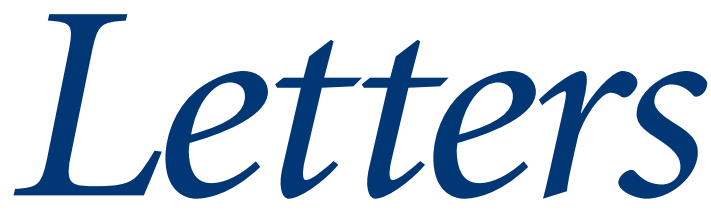

All letters are subject to editing and may be shortened. Letters should be sent to the BJGP office by e-mail in the first instance, addressed to journal@rcgp.org.uk (please include your postal address). Alternatively, they may be sent by post as an MS Word or plain text version on CD or DVD. We regret that we cannot notify authors regarding publication. Letters not published in the Journal may be posted online on our Discussion Forum. For instructions please visit: http://www.rcgp.org.uk/bjgp-discuss

\section{Sick children}

James Cave provides a good comment on the articles about management of acutely ill children. ${ }^{1}$

It seems barely credible that British GPs fail to use basic, simple tests such as pulse, respiration, capillary return, and temperature in assessing acutely ill children. Perhaps they see so few really ill children in a year that they can get away with it.

I wonder what they do in the 15 or 20 minute consultations after making the general observation that the child is either well or ill!

A 1960s film was titled The Knack ... and How to Get It. I believe it referred to chat up lines by young men. If being a careful family doctor is just to do with a acquiring the knack for safe diagnosis all well and good, but without a systematic approach, 'general impression' is bound to fail some children.

In my practice I do not have the luxury of a paediatrician at a referral centre or an ambulance service to rescue the cases that I miss. Here in rural Gambia our locally-trained (school grade 9) nurses are taught the four observations (as stated above and by Cave) which should be used with any ill child, supplemented by a simplified coma score (Blantyre coma score). Results are reproducible from observer to observer and an urgent request for the doctor to see the sick child is the result. I tend to repeat the same observations to confirm the severity of the case, en route to a diagnosis and treatment.

The proviso is that WHO Integrated Management of Childhood Illness guidelines suggest actually counting respiratory rate for a full, timed minute.
Perhaps a minute is too long for highly trained doctors to sit still and count, but I would suggest that this can be a quiet interlude in which to allow parents and the child to watch you take a careful, objective view. Following that, most doctors can listen to the family while counting the (usually regular) pulse.

Brandishing a stethoscope is not likely to help any further and anyway stops the clinician from hearing the family while his/her ears are blocked!

Poor overall appearance of the child is also important, but parents with their own children are just as likely to tell you this without the benefit of any medical training, particularly for a child who you have not seen recently.

As a junior anaesthetist I learned that risks drop to rarities when you do things systematically. GPs could do well to take the same line.

\section{James Erskine}

Sibanor Rural Health Centre, PO Box 86 Banjul, The Gambia. E-mail: erskinesjd@yahoo.co.uk

\section{REFERENCE}

1. Cave J. Managing the acutely ill child. Br J Gen Pract 2008; 58(549): 228-229.

DOI: 10.3399/bjgp08X302718

\section{Alcohol policies}

An essay in the April issue of the $B J G P^{1}$ spells out clearly the need for a truly 'strategic', multilevel policy response to the growing problem of alcohol-related illness in the UK. Even in core primary care services, like maternity care or family planning, patterns of alcohol use across the lifespan cause multi-faceted problems. ${ }^{2}$ Within schools' revised personal, social, and health education programme, alcohol education is a prominent area, but we are struggling now to create good learning materials and to build confidence among teachers that they can help 'make being drunk socially unacceptable'.'

My own accumulating observations in community settings, around domestic violence, or children entering local authority care, just drove me to join the new special interest group for Alcohol and Violence (launched by the UK Public Health Association). At the political level, we need to "resist corporate pressure"1 not just from the alcohol industry but from a wider leisure and tourism sector that has a powerful hold over the present government. At a professional level, too, we ought to acknowledge that most NHS provision for alcohol dependence is ineffective, and that alcoholics stay away in droves! ${ }^{3}$

In the course of re-thinking our alcohol services, it may be useful to look at more effective partnerships between health professionals and the voluntary sector, as this appears to be synergistic in helping patients with alcohol, family, and employment problems. ${ }^{4}$ Across England, local authorities and primary care trusts are now working out specific priorities for 'local area agreements', within which healthy communities are a national priority. GPs are uniquely placed to introduce credible and creative ideas around alcohol into these local agreements.

\section{Woody Caan}

Professor of Public Health, Department of Child and Family Health, East Road, Cambridge, CB1 1PT.

E-mail: a.w.caan@anglia.ac.uk

\section{REFERENCES}

1. Mirza ZA, Lakasing E. Government strategy on alcohol. Time to revise legislation and implement wider interventions. Br J Gen Pract 2008; 58(549): 286-287. 